
\title{
COBERTURA DE ANALISTAS DE MERCADO E
SOCIAL DISCLOSURE: EVIDENCIAS EM EMPRESAS
BRASILEIRAS ABERTAS
}

\author{
Rafael Xavier de Oliveira' \\ Rodrigo de Souza Goncalves ${ }^{2}$ \\ Otávio Ribeiro de Medeiros ${ }^{3}$ \\ Bruno Vinícius Ramos Fernandes ${ }^{4}$
}

Resumo: O presente artigo tem por objetivo testar a hipótese de que há relação entre cobertura de analistas de mercado e nível de social disclosure (SD) em empresas brasileiras abertas, e que esta relação é positiva ( $\mathrm{H} 1)$. A referida hipótese assume que o papel exercido pelos analistas de mercado faz com que as empresas melhorem seus padrões de evidenciação, aumentando seu nível de evidenciação ao longo do tempo $(\mathrm{H} 2)$, incluindo o de natureza social. Para testar as hipóteses, foram avaliados os relatórios de 86 empresas listadas no Índice Brasil 100 (IBrX-100) da Bolsa de Valores, Mercadorias e Futuros de São Paulo (B3), no período de 2005 a 2014. Por meio de análise descritiva, identificou-se que há uma tendência de maior nível de SD à medida que há uma maior cobertura de analistas. Adicionalmente, por meio de regressões com dados em painel com efeitos fixos seccionais estimadas por SUR, foi possível verificar que as variáveis Fundos Socialmente Responsáveis e Internacionalização são significativas e positivamente relacionadas com o nível de evidenciação social. Quanto à cobertura dos analistas de mercado, esta também se apresentou significativa (2005-2014), corroborando com a H1, de que o acompanhamento por analistas de mercado interfere positivamente no nível das informações sociais apresentado pelas empresas. Por outro lado, a $\mathrm{H} 2$ não foi corroborada, ocorrida tanto pela tendência de diminuição no nível de social disclosure, como pela não persistência na divulgação ocorrida em $76 \%$ das empresas analisadas. Verificou-se também uma mudança no padrão de variáveis, haja vista que fatores como setor, tamanho, endividamento e auditoria não foram determinantes para o aumento no nível de evidenciação social no período analisado de 2005-2014, conforme se observa em estudos anteriores. Por fim, os resultados apontam que empresas com maior divulgação social passam a ter maior atenção da imprensa especializada, isto é, maior cobertura de analistas.

Palavras-chave: Social Disclosure. Determinantes do Social Disclosure. Cobertura de Analistas de Mercado.

\footnotetext{
'rafael_oliveira1@yahoo.com.br - Universidade de Brasília

2rgoncalves@unb.br - Universidade de Brasília

rgoncalves@unb.br - Universidade de Brasília

bv.ramos@gmail.com - Universidade de Brasília

- A primeira versão desse artigo foi apresentada no XVII USP International Conference Acconting e os autores agradecem as contribuições recebidas pelos pareceristas da mencionada conferência, bem como pelos congressistas que apresentaram sugestões de melhoria. Os autores agradecem as contribuiçōes dos pareceristas, que possibilitaram uma série de melhorias ao artigo. Naturalmente, os erros eventuais aqui cometidos são de exclusiva responsabilidade dos autores.

- Artigo submetido em: 01/06/2017. Aceito em: 05/04/2018.
} 


\section{COVERAGE OF MARKET ANALYSTS AND SOCIAL DISCLOSURE: EVIDENCES IN BRAZILIAN COMPANIES}

Abstract: This paper is aimed at testing the hypothesis that there is a relationship between market analysts' coverage and a higher level of social disclosure (SD) in Brazilian listed companies, and that this relationship is positive $(\mathrm{H} 1)$. This hypothesis assumes that the role played by market analysts causes firms to improve their disclosure patterns, increasing their level of disclosure over time ( $\mathrm{H} 2)$, including that of a social nature. To test the research hypotheses, the reports of 86 companies listed on the B3's $\mathrm{IBrX}-100$ index were evaluated between 2005 and 2014. By means of a descriptive analysis, it was possible to identify a trend towards a higher level of SD when a greater coverage of analysts occurs. Additionally, using panel data regressions with cross-sectional fixed effects estimated by SUR, it was possible to attest that variables "Socially Responsible Funds" and "Internationalization" are significant and positively related with the level of social disclosure. As for the coverage by market analysts, this also proved to be significant (2005-2014), wich supports that $\mathrm{H} 1$, meaning that the work analysts' coverage interferes positively with the level of social information disclosed by companies. On the other hand, $\mathrm{H} 2$ was not confirmed, due both to the decline in the level of social disclosure and to the nonpersistence of disclosure in $76 \%$ in the sample. There was also a change in the pattern of variables that determine the level of social disclosure, since variables such as industry, size, indebtedness and audit did not contribute with an increase in the level of social disclosure over the entire period of 2005-2014, as observed in previous studies. Finally, the results indicate that companies with the greater social disclosure are obtaining more attention from the specialized press, that is, greater coverage by analysts.

Keywords: Social Disclosure. Determinants of Social Disclosure. Market Analysts Coverage. 


\section{INTRODUÇÃO}

E m um mercado competitivo, a busca por um maior espaço, aceitação e reconhecimento pela sociedade e por investidores faz com que as empresas realizem ações para tornarem-se mais atrativas, transparentes e promotoras do desenvolvimento econômico sustentável (Gonçalves et al., 2013; Jo \& Harjoto, 2014).

Nessa direção, cada vez mais as empresas buscam valer-se de ações de responsabilidade social (CSR), de modo a mitigar as chamadas externalidades negativas (Baron, 2001; Heal, 2005). Assim, presume-se que tais ações contribuam para o que Ramanathan (1976) chama de "contrato social", dada a figura da bilateralidade: as organizações realizam investimentos na esfera social e buscam uma maior aceitação dos diversos stakeholders, inclusive a sociedade; esta, por outro lado, recebe os benefícios inerentes às ações sociais.

Uma das consequências de tais ações, segundo Jo e Harjoto (2014) e Cahan et. al. (2014), é que organizações que combinam ações sociais e maior divulgação discricionária passam a ter maior atenção por parte da imprensa especializada (analistas) e, em sua maioria, recebem avaliações positivas, que acabam por agregar à sua imagem reputacional.

Contudo, é importante destacar que tais medidas demandam recursos empresariais e que, na visão de autores como Friedman (1970) e Bhandari e Javakhadze (2017), as empresas não deveriam alocar recursos fora de sua atividade operacional, seja porque não foram constituídas para essa finalidade ou porque diminuem sua eficiência alocativa. Tais críticas são relevantes sobretudo porque a divulgação das informações sociais encontra-se em um contexto de discricionariedade do gestor, abrindo espaço para um comportamento oportunista, especialmente em países com estruturas deficitárias de proteção ao investidor (Abernathy et al, 2017; Martínez-Ferrero; Villarón-Peramato \& García-Sanchez, 2017).

Assim sendo, o papel exercido pelos agentes que monitoram as ações do gestor, incluindo os analistas de mercado, pode minimizar essa discricionariedade passando a exigir maior divulgação, inibindo decisões que maximizem sua utilidade pessoal (Jo \& Harjoto, 2014).

Nesse cenário, os analistas de mercado ou analistas financeiros, atuam como um dos principais intermediários da informação nos mais diversos mercados financeiros, juntamente com a área contábil, com as firmas de auditoria independentes e as empresas de classificação de risco (agências de rating), justamente por desempenharem esse papel de canal de comunicação (Vasconcelos et. al., 2008).

Sua atuação consiste em coletar as informações divulgadas pelas companhias, processar e emitir pareceres que buscam elucidar as melhores possibilidades para o usuário quanto à alocação de seus recursos, possuindo um papel relevante sob a ótica da eficiência do mercado, ao contribuírem com a difusão da informação e redução da assimetria informacional (Schipper, 1991; Healy \& Palepu, 2001; Martinez, 2004; Bradley, Gokkaya \& Liu, 2017).

Desse modo, os analistas de mercado atuam no monitoramento das organizações, pressionando a administração com questionamentos técnicos e específicos, motivados pelas necessidades e anseios dos investidores e, naturalmente, munidos de informações obtidas dentro dos ambientes mais privados das companhias (atuação que o investidor comum não tem como realizar), onde eles mantêm boas relações.

Nesse ambiente, uma maior cobertura por parte dos analistas de mercado pode inibir o comportamento oportunista do gestor, fazendo com que, ao divulgar informações de natureza voluntária, incluindo as de natureza social, estas tenham valor informativo para a análise do risco da organização 
e, com isso, tais informações exerçam um papel estratégico para as companhias (Orlitzky \& Benjamin, 2001; Saiia, Carroll \& Buchholtz, 2003).

À medida que isso ocorre, tais organizações podem ser positivamente avaliadas pelo mercado e seus analistas, principalmente na ótica de serem boas oportunidades de investimento, por serem percebidas como de menor risco e maior reputação (loannou \& Serafeim, 2010; Beuren et al., 2010; Gonçalves et. al., 2013; Lee, 2017).

Considerando o cenário ora mencionado, pode-se indagar se há relação entre o monitoramento realizado por analistas de mercado e um maior nível de social disclosure em empresas brasileiras abertas. Para tanto, tem-se por objetivo verificar se uma maior cobertura por analistas de mercado contribui para um maior nível de social disclosure em empresas brasileiras abertas.

Este estudo justifica-se, inicialmente, pela importância que o tema representa no contexto moderno das organizações e da sociedade. Sob a ótica de estudos anteriores (p.e. Gray et. al.; 2001; Richardson \& Welker, 2001; Campbell, Moore \& Shrives, 2006; Clarkson et al., 2008; Murcia \& Santos, 2009; Rover, 2013; Moraes, Gonçalves \& Niyama, 2015), que tratam dos determinantes da evidenciação social, não foram realizadas análises que investigassem se um monitoramento mais intenso exercido pelos analistas de mercado promoveria um nível mais elevado de social disclosure, especialmente em países com baixa proteção ao investidor, como é o caso brasileiro.

Ainda sob essa ótica, por se tratarem de atividades fora do escopo principal da organização e de itens que podem receber pouca ou até nenhuma atenção por parte dos analistas de mercado, abre-se a possibilidade para o gerenciamento do gestor quanto à prestação de contas dos recursos alocados nas referidas atividades. Portanto, esta pesquisa lança uma análise diferente em relação aos estudos de Dhaliwall et al. (2012) e Lee (2017) que trataram da acurácia na previsão dos analistas face à divulgação social, uma vez que ela busca compreender se a cobertura dos analistas é um determinante ou mecanismo de incentivo para uma maior divulgação das atividades do CSR.

\section{REFERENCIAL TEÓRICO}

\subsection{Cobertura de analistas e seu papel no mercado de capitais}

A busca pela convergência de interesses comuns advindos da relação entre agente e principal é objeto de ações e mecanismos para que a assimetria existente possa ser a menor possível e, com isso, as ações do agente (gestor) sejam convergentes com o do principal (acionistas). É nesse contexto que surgem os analistas de mercado como um dos mecanismos de monitoramento.

Martinez (2004) afirma que os analistas de mercado são vistos como profissionais que avaliam o desempenho presente e as perspectivas futuras das companhias abertas, atuando como canais de transferência de informações aos segmentos menos informados, repassando ao usuário suas análises. Com tal comportamento, os analistas cumprem a função de agentes mitigadores da assimetria informacional, contribuindo dentre outros aspectos para a eficiência de mercado.

O ponto central do trabalho dos analistas de mercado é perscrutar a situação econômico-financeira atual e prospectiva das empresas. Porém, Healy e Palepu (2001) e Yu (2008) sugerem que eles desempenham um papel adicional, que é a de detecção do comportamento inapropriado por parte dos gestores e administradores no tocante à discricionariedade no tratamento dos números contábeis. Num contexto adicional, também podem contribuir para a eficiência e lisura do mercado de capitais, segundo Dyck, Morse e Zingales (2006) e Martinez (2009), ao se depararem, em suas análises, com fraudes corporativas. 
Já para Brennan e Subrahmanyam (1995), Brennan e Tamarowski (2000), Irvine (2003) e Roulstone (2003), um dos maiores benefícios do trabalho realizado pelos analistas de mercado é adicionar valor à empresa, diminuindo o custo de capital, consequência natural de um maior acesso dos investidores à informação, gerando uma espécie de ciclo virtuoso, pois: com mais informações disponíveis, maior é a visibilidade das empresas no mercado, maior a segurança por parte dos investidores e, consequentemente, maior o impacto positivo no volume de papéis negociados, gerando maior liquidez às ações.

Elgers, Lo e Pfeiffer (2001) e Martinez (2009) salientam que a maior cobertura de analistas em uma determinada firma é geralmente associada a um alto nível de eficiência do preço das ações com respeito às informações financeiras publicamente disponíveis. Os aspectos ora mencionados são potencializados quando se trata de empresas denominadas socialmente responsáveis, seja porque sinalizam aos analistas uma maior reputação corporativa e menor risco (Roberts \& Dowling, 2002; Ferreira, 2004; Lee, 2017), seja em virtude de divulgarem informações que melhoram a previsão dos referidos agentes (Dhaliwal et. al., 2012; Cormier \& Magnan, 2014).

Os resultados dos estudos de Dhaliwal et. al. (2012) e Lee (2017) apontam que as organizações socialmente responsáveis possuem melhores práticas de divulgação e, consequentemente, menor assimetria informacional, contribuindo com as previsões dos analistas, na medida em que realizam previsões mais acuradas acerca dos resultados futuros de tais empresas.

Jo e Harjoto (2014) e Cahan et. al. (2014) apontam que empresas com tais características (socialmente responsável e com maior divulgação discricionária) recebem melhores avaliações dos analistas, o que por sua vez resulta em maior reputação corporativa.

No fundo, o que se observa, segundo Ferreira (2004) e Lee (2017), é que tais empresas, ao incorporarem em suas ações organizacionais aspectos conceituais do CSR, dispõem de uma melhor governança e ética, que culminam em informações de melhor qualidade, incluindo as de natureza discricionária.

\subsection{Evidenciação social - a busca da legitimidade das ações empresariais}

Segundo Verrecchia (2001), os gestores devem dispor de incentivos para realizarem a divulgação, especialmente a de natureza discricionária, dentre elas aquela baseada no julgamento. É nesse escopo que diversas pesquisas buscam compreender o ambiente no qual se situam as organizações e que incentivos estão atrelados à maior e melhor divulgação discricionária, dentre elas a de natureza social.

De uma forma geral, as empresas evidenciam informações sociais para promoverem o conhecimento sobre suas atividades com vistas a legitimar seus comportamentos, ações, decisões, bem como projetar seus valores e ideias em resposta a fatores externos (Riahi-Belkoui \& Korpik, 1989; Gray et. al., 2001).

Por meio da divulgação de informações socioambientais, espera-se que os usuários sejam providos de informações mais completas para analisar o comportamento da organização de forma mais ampla, podendo identificar ações sociais que mostram o papel da empresa como agente participativo e preocupado com a evolução de todos os aspectos envolvidos e não somente com seus produtos e resultados financeiros (Parsa \& Kouhy, 2001; Beuren et. al., 2010).

Nesse sentido, as empresas tendem a aperfeiçoar suas práticas de evidenciação como forma de torná-las um mecanismo de redução da assimetria informacional e de maior transparência (Lee, 2017) na busca de maior credibilidade e reputação por parte dos investidores, bem como dos demais stakeholders (Riahi-Belkaoui \& Karpik, 1989; Riahi-Belkaoui, 2004; Jo \& Harjoto, 2014). 
Para Beuren et al. (2010), quando as empresas disponibilizam informações fidedignas e transparentes de sua conduta e de seu papel social enquanto organização, elas tornam-se relevantes, diferenciadas e até mais legítimas com relação às demais, podendo angariar ganhos dentro do mercado; transmitem maior segurança (Cabral, 2015) e impulsionam investimentos com menor grau de risco, com sustentabilidade e probabilidade de maior valorização. Tais aspectos também foram observados nos estudos de Dhaliwal et al. (2011), Reverte (2012) e Gonçalves et al. (2013).

A divulgação de tais ações pode revelar importantes aspectos acerca do planejamento e ações de CSR, o que serviria como instrumento de verificação dos cuidados para com o uso e alocação dos recursos, bem como da efetividade dos mesmos como redutores de externalidades negativas (Riahi-Belkaoui, 2004; Hammond \& Miles, 2004).

Tais pontos possuem características que podem contribuir para uma análise mais completa pelo investidor e pelo analista de mercado sobre o modo como a empresa tem utilizado os recursos disponíveis para seu crescimento e para a maximização da riqueza dos acionistas, contribuindo para melhoria de suas previsões (Dhaliwal et. al., 2012; Cormier \& Magnan, 2014). Do contrário, se a prática for a realização de ações para promoção da imagem organizacional, sem o devido planejamento acerca da alocação dos recursos, tal atitude poderia resultar em um impacto negativo na imagem e reputação da empresa (Hillman \& Keim, 2001), uma vez que, as informações serão avaliadas como um meio de transmitir uma imagem que não corresponde à realidade, constituindo-se numa forma de gerenciamento de impressão (Hooghiemstra, 2000; Cormier \& Magnan, 2014).

Hooghiemstra (2000) apresenta resultados de estudos que identificaram, especialmente em setores de alto impacto ambiental, que os relatórios serviram de instrumento para mitigar a impressão dos usuários externos a respeito dos impactos negativos de suas atividades operacionais.

É sob esse ponto que Dhaliwal et al. (2012) e Cormier e Magnan (2014) discutem o papel da credibilidade das informações sociais, especialmente em razão destas não serem auditadas e, com isso, o espaço que há para questionamentos acerca de sua fidedignidade (gerenciamento de impressão). Um dos aspectos mencionados por Cormier e Magnan (2014) é o fato de a organização declarar a realização de ações de responsabilidade social, entretanto, os resultados de tais ações não representarem benefícios concretos à sociedade.

Apesar da hipótese levantada por tais estudos, os resultados de Dhaliwal et al. (2012) revelam que, das empresas analisadas, a divulgação do CSR está associada à melhor acurácia na previsão dos analistas. Adicionalmente, empresas que aumentaram a transparência de suas ações sociais passaram a obter um prêmio pela redução do risco (Orlitzky \& Benjamin, 2001; Dhaliwal et al., 2011; Calegari et. al., 2016). Do ponto de vista do investidor externo, é importante que os relatórios sociais desempenhem esse papel, pois é por meio dele que se reduzirá parte das incertezas quanto ao alinhamento dos interesses do agente (gestor) e principal (acionista).

Nesse contexto, observa-se que pode ocorrer um ciclo virtuoso à medida que uma maior cobertura de analistas em empresas que realizam ações de responsabilidade social seja um incentivo para melhoria na divulgação discricionária (Jo \& Harjoto; 2014; Cahan et. al., 2014) e que tais relatórios, por transmitirem melhor qualidade informacional, estejam associados à maior acurácia na previsão dos analistas (Dhaliwal et. al., 2012; Cormier \& Magnan, 2014). Assim sendo, tem-se a primeira hipótese do estudo:

H1: A intensidade da cobertura de analistas das empresas brasileiras abertas está positivamente relacionada com o nível de social disclosure.

Adicionalmente, ante os aspectos que fundamentam as ações de responsabilidade social e aos benefícios gerados na reputação organizacional pela redução da assimetria informacional e maior 
transparência (Lee, 2017) bem como menor risco sistemático (Orlitzky \& Benjamin, 2001; Dhaliwal et al., 2011; Calegari et. al., 2016), espera-se haver uma maior persistência em se melhorar o nível de social disclosure. Assim sendo, tem-se a segunda hipótese do estudo:

H2: Existe uma tendência persistente, ao longo do tempo, de melhoria do nível de social disclosure por parte das empresas brasileiras abertas.

\section{METODOLOGIA}

Inicialmente, o objeto de estudo é formado por empresas brasileiras listadas no índice IBrX-100 da BM\&FBovespa, dada sua representatividade. Uma vez definido o objeto de estudo, foram selecionadas as empresas que tiveram acompanhamento por parte dos analistas de mercado no período de 2005 a 2014.

A partir dos dados disponíveis na Bloomberg ${ }^{\circledR}$, das 98 ações que compunham tal índice ao final de 2014, foram excluídas, para evitar a dupla contagem, as ações das empresas com menor histórico de dados que apresentaram tanto ações ordinárias (ON) como preferenciais (PN), que totalizaram seis. Posteriormente, também foram excluídas as ações das companhias controladas por alguma outra já integrante do portfólio, pois a coleta de dados da controladora, contempla os dados da controlada ou subsidiária, em um total também de 6 empresas. Assim, a amostra final estudada totaliza 86 empresas.

Destaca-se que, a amostra final é desbalanceada no corte temporal, pois das empresas componentes da amostra, apenas 43 possuíam capital aberto em 2005, ano de início da coleta de dados e, portanto, apenas estas possuíam cobertura de analistas para aquele ano; as demais 43 abririam seu capital no decorrer dos anos estudados, passando a obter cobertura de analistas somente a partir desse momento, influenciando, desta forma, a quantidade de empresas estudadas por ano. Para avaliar as informações sociais (variável dependente) foi utilizada a métrica elaborada por Gonçalves et al. (2014) que avalia de forma quali-quantitativa as informações de projetos sociais divulgadas pelas companhias. O índice de social disclosure (ISD), elaborado e validado por Gonçalves et. al. (2014), fundamenta-se nos estudos de Ramanathan (1976), Haydel (1989) e Hammond e Miles (2004) e encontra-se sintetizado no Anexo 1.

Os itens mencionados no referido anexo são classificados em uma escala que varia entre restrito, baixo, médio e amplo, permitindo obter o índice de social disclosure de um mínimo de 13 pontos para as variáveis que obtiverem todos os resultados "restritos" e um máximo de 52 pontos para aquelas que obtiverem "amplo" para todos os itens avaliados. Para tanto, foram utilizados os relatórios anuais e de sustentabilidade (RAS) na avaliação da informação social e, na ausência de tais relatórios, foi utilizada a demonstração financeira padronizada (DFP). A Tabela 1 apresenta a quantidade de empresas estudadas por ano, bem como a quantidade e o tipo de relatório utilizado para obtenção da informação social.

Tabela 1: Estatísticas descritivas do uso de controles gerenciais

\begin{tabular}{|c|c|c|c|c|c|}
\hline Ano & \multicolumn{2}{|c|}{ Relatório } & Ano & \multicolumn{2}{c|}{ Relatório } \\
\hline 2005 & DFP & RAS & 2006 & DFP & RAS \\
\hline 43 & 4 & 39 & 49 & 6 & 43 \\
\hline 2007 & DFP & RAS & 2008 & DFP & RAS \\
\hline 66 & 16 & 50 & 71 & 20 & 51 \\
\hline 2009 & DFP & RAS & 2010 & DFP & RAS \\
\hline 74 & 18 & 56 & 78 & 23 & 55 \\
\hline 2011 & DFP & RAS & 2012 & DFP & RAS \\
\hline 82 & 21 & 61 & 84 & 21 & 63 \\
\hline 2013 & DFP & RAS & 2014 & DFP & RAS \\
\hline 86 & 23 & 63 & 86 & 23 & 63 \\
\hline
\end{tabular}


A tabela identifica que, em 2005, a amostra da pesquisa foi de 43 empresas, pois apenas estas possuíam cobertura de analistas de mercado para aquele ano. No ano em questão, dos 43 relatórios, a qualidade da informação social foi obtida a partir da análise de 4 DFP's, enquanto que para as outras 39 empresas, foi analisado o RAS. A dinâmica de interpretação da tabela é a mesma para os demais anos e, ao final desses anos, tem-se 719 documentos.

Outro ponto importante a se destacar é que a utilização da DFP foi realizada para os casos de não divulgação do RAS, visto que suas informações são predominantemente de caráter econômico-financeiro, trazendo prejuízos para a análise da informação social.

Em relação às variáveis independentes, exceto cobertura de analistas, foi possível, a partir de estudos anteriores, identificar os determinantes do nível de evidenciação social, que são: setor, tamanho, endividamento, internacionalização, auditoria e participação em fundos socialmente responsáveis (Gray et. al.; 2001; Richardson \& Welker, 2001; Campbell, Moore \& Shrives, 2006; Clarkson et al., 2008; Murcia \& Santos, 2009; Rover, 2013; Gonçalves et. al., 2014; Moraes, Gonçalves \& Niyama, 2015). Para tais variáveis, espera-se uma relação positiva para com a variável dependente - ISD.

Já para a variável cobertura dos analistas, também espera-se uma associação positiva para com o ISD, considerando o papel exercido pelos analistas como redutores da assimetria informacional demonstrado em pesquisas anteriores (Healy \& Palepu, 2001; Irvine, 2003; Martinez, 2004; Louis \& Robinson, 2005; Houston, Lev \& Trucker, 2006; Martinez, 2009; Jo \& Harjoto; 2014; Cahan et al., 2014; Dhaliwal et al., 2012).

Para testar a $\mathrm{H} 1$, um modelo econométrico foi especificado na forma de painel conforme a seguir:

$$
Y_{i t}=\alpha+\gamma X_{i t}+\boldsymbol{\delta}^{\prime} \mathbf{Z}_{i t}+u_{i t}
$$

onde: $Y_{\text {it }}$ - é a variável índice de social disclosure; a é a constante da regressão; $\gamma$ é o coeficiente associado a Xit, que é a variável cobertura de analistas, mensurada pelo logaritmo natural (Ln) da quantidade de analistas (obtida no terminal da Bloomberg ${ }^{\circledR}$ ) que cobrem a empresa i no momento $t ; \mathrm{u}_{\mathrm{it}}$ é o erro aleatório da regressão, com a premissa $u_{i t} \sim N\left(0, \sigma^{2}\right)$; $\delta$ é um vetor coluna $7 \times 1$ de coeficientes das variáveis de controle e $Z_{\text {it }}$ é um vetor coluna $7 \times 1$ das variáveis de controle, descritas a seguir:

1) Setor (S) - variável binária, com valor de (1) para as empresas consideradas "sensíveis" e (0) para as "não sensíveis", conforme embasamento na Lei 10.165/2000, definida conforme a classificação proposta no sítio da B3.

2) Tamanho $(T)$ - representado pelo logaritmo natural $(L n)$ da receita operacional líquida (período de 2005-2014) e pelo ativo total (período de 2005-2009 e 2010-2014) das empresas que compõem a amostra, ambos os dados obtidos no terminal da Bloomberg ${ }^{\circledR}$. Tal procedimento foi adotado uma vez que ele tornou mais robusto a estimação da equação (1).

3) Endividamento (E) - representada pela relação entre capital de terceiros e ativo total, ao final de cada ano, também obtida no terminal da Bloomberg ${ }^{\circledast}$.

4) Internacionalização (I) - variável binária, conforme ocorrência de negociação das ações da companhia, discriminando se ela é negociada somente no mercado local ou se também é negociada nos EUA e Europa. Variável obtida no terminal da Bloomberg ${ }^{\oplus}$.

5) Auditoria (A) - variável binária, onde atribuiu-se o valor de (1) para os relatórios de empresas que são auditados por firmas independentes de uma das "big four" ou (0) se não. Variável obtida a partir dos relatórios anuais e DFP's das companhias. 
6) Fundos Socialmente Responsáveis (F) - variável binária, onde (1) são as empresas que participam do ISE e ICO $\mathrm{ICO}_{2}$ B3 e (0) se são empresas que não participam. Variável obtida a partir das listagens de cada um dos fundos disponíveis no sítio da B3.

7) Efeito da alteração na legislação societária (Conv) - a adoção obrigatória das IFRSs para as empresas brasileiras promoveu variações no resultado das empresas se comparado com o período anterior à sua promulgação. Para tanto, no modelo em que foi realizado o teste para o período completo (20052014), foi utilizada uma variável binária que classificou o período anterior a 2010 como (0) e o período de 2010 em diante como (1), a fim de controlar os efeitos em razão da mudança do padrão contábil.

As variáveis de controle foram inseridas no modelo a fim de proporcionar maior robustez aos resultados encontrados, pois, embora tais variáveis não sejam objeto do estudo, a variável dependente (índice de social disclosure) pode ser influenciada por elas.

De modo a compreender o efeito das variáveis "índice de sustentabilidade empresarial" (ISE), do "índice social disclosure" (ISD) e "cobertura de analistas", foi realizado o teste de causalidade de Granger. O referido teste de causalidade pode ser empregado no sentido estrito para avaliar a precedência na relação entre variáveis. Por mais que as variáveis tenham relação estatística significante, não se pode afirmar que exista causalidade entre variável independente e dependente elencadas na equação (1), pois o método de regressão linear capta apenas o movimento conjunto das variáveis ao longo do tempo. Para tanto, os resultados do teste de causalidade de Granger permitem avaliar se existe alguma ação que precede a variável testada, permitindo inferir, por exemplo, se maior cobertura de analistas precede o aumento do nível de social disclosure.

Para testar $\mathrm{H}_{2}$, foi adaptado o modelo de Sloan (1996) para teste de persistência dos lucros, no sentido de que, caso o ISD mantenha o comportamento ao longo do tempo, tal fato será corroborado se for verificada a persistência do índice, constatada a significância do coeficiente de um modelo autoregressivo de primeira ordem, $\operatorname{AR}(1)$, conforme descrito na equação a seguir:

Onde:

$$
I S D_{i, t}=\alpha+\beta I S D_{i, t-1}+e_{i, t}
$$

$I S D_{i, t}=$ é a medida do nível de social disclosure da i-ésima empresa, no período t;

$\mathrm{ISD}_{\mathrm{i},-\mathrm{t}}=$ é a medida do nível de social disclosure da i-ésima empresa, no período anterior;

$a=$ é a constante da regressão;

$\beta=$ é o coeficiente do termo autoregressivo da regressão;

$\mathrm{e}_{\mathrm{i}, \mathrm{t}}=$ é o termo de erro estocástico, assumindo-se normalidade, isto é $\mathrm{e}_{\mathrm{i}, \mathrm{t}} \sim \mathrm{N}\left(0, \sigma^{2}\right)$.

Importa destacar que foi realizada a estimação dos dados conforme a equação (2) para cada uma das empresas que compõe o estudo e verificada a significância aos níveis de 1\%, 5\% e 10\%, para então atribuir se há persistência ou não na informação.

\subsection{Limitações da Pesquisa}

Para análise do ISD foram utilizados, inicialmente, os relatórios de sustentabilidade e, em caso de não publicação destes, os relatórios anuais. Porém, houve empresas que não fizeram a publicação de nenhum deles. Nesses casos, houve o contato via correio eletrônico e, em certas situações, a resposta recebida foi que, de fato, a companhia não havia publicado tais relatórios em nenhum dos anos solicitados e em algumas outras situações não houve sequer resposta.

Houve, ainda, casos de empresas que publicaram os relatórios sociais em alguns anos e em outros não. Para essas empresas, usou-se a mesma tratativa (contato via correio eletrônico). Para tentar minimizar a ausência desses dados, utilizaram-se as DFP's, mas que não possuem tantas informações de 
cunho socioambiental quanto os relatórios sociais. Wallace e Naser (1995) apontam como qualidade restrita da informação esses tipos de casos, ou seja, quando a informação se encontra pouco presente.

Também pode-se mencionar o que Murcia e Santos (2009) afirmam, de que não é possível ter total convicção se as empresas, de fato, não divulgaram tais informações por não possuírem dados acerca do assunto ou se foi porque elas decidiram, por algum motivo, simplesmente não as divulgarem.

Pode-se considerar também como uma limitação a amostragem, que, por ser intencional (não aleatória), faz com que os resultados obtidos possam, eventualmente, não serem replicados para todas as outras empresas não componentes da seleção.

\section{ANÁLISE DOS RESULTADOS}

A análise dos resultados está dividida em três partes, a saber: a) análise descritiva de todas as variáveis no período pré-convergência (2005-2009) e pós-convergência (2010-2014), cujo objetivo é analisar a distribuição dos dados das referidas variáveis (tabela 2); b) análise descritiva das variáveis ISD e cobertura dos analistas, cujo objetivo é analisar a tendência existente entre elas, no período de 2005 a 2014 (tabelas 3 e 4); e, por fim, c) estimação dos dados em painel e teste de causalidade de Granger (tabelas 5 e 6), cujo objetivo é compreender em que medida a maior cobertura dos analistas relaciona-se positivamente com o nível de social disclosure $\left(\mathrm{H}_{1}\right)$ bem como a persistência quanto à melhoria do nível de social disclosure $\left(\mathrm{H}_{2}\right)$.

Tabela 2: Estatística descritiva das variáveis do estudo

\begin{tabular}{|c|c|c|c|c|c|c|c|c|c|}
\hline 2005-2009 & $\mathrm{COB}$ & SETOR & ALAV & INTER & AUD & FUNDOS & REC & ATIVO & ISD \\
\hline Média & 11,1023 & 0,3828 & 0,3055 & 0,5050 & 0,8647 & 0,3663 & 19,2630 & 22,2707 & 29,5281 \\
\hline Mediana & 10,0000 & 0,0000 & 0,2924 & 1,0000 & 1,0000 & 0,0000 & 26,4356 & 30,1366 & 31,0000 \\
\hline DP & 5,8772 & 0,4868 & 0,1637 & 0,5008 & 0,3426 & 0,4826 & 13,6959 & 14,6086 & 8,8593 \\
\hline Mínimo & 0,0000 & 0,00 & 0,00 & 0,00 & 0,00 & 0,00 & 0,00 & 0,00 & 13,00 \\
\hline Máximo & 27,0000 & 1,00 & 0,94 & 1.00 & 1,00 & 1.00 & 36,72 & 38,96 & 51,00 \\
\hline 2010-2014 & $\mathrm{COB}$ & SETOR & ALAV & INTER & AUD & FUNDOS & REC & ATIVO & ISD \\
\hline Média & 14,7861 & 0,3462 & 0,3316 & 0,6563 & 0,9327 & 0,5553 & 21,5901 & 25,2178 & 28,3293 \\
\hline Mediana & 15,0000 & 0,0000 & 0,3245 & 1,0000 & 1,0000 & 1,0000 & 23,0272 & 25,7451 & 30,0000 \\
\hline DP & 5,0543 & 0,4763 & 0,1700 & 0,4755 & 0,2508 & 0,4975 & 6,9184 & 5,2695 & 7,7989 \\
\hline Mínimo & 0,00 & 0,00 & 0,01 & 0,00 & 0,00 & 0,00 & 0,00 & 0,00 & 14,00 \\
\hline Máximo & 26,00 & 1,00 & 0,89 & 1,00 & 1,00 & 1,00 & 31,70 & 34,18 & 44,00 \\
\hline $2005-2014$ & $\mathrm{COB}$ & SETOR & ALAV & INTER & AUD & FUNDOS & REC & ATIVO & ISD \\
\hline Média & 13,23 & 0,3616 & 0,3206 & 0,5925 & 0,9040 & 0,4757 & 20,4265 & 23,7442 & 28,8345 \\
\hline Mediana & 14,00 & 0,0000 & 0,3127 & 1,00 & 1,00 & 0,0000 & 24,1953 & 27,2020 & 31,0000 \\
\hline DP & 5,71 & 0,4808 & 0,1678 & 0,4917 & 0,2947 & 0,4997 & 10,9059 & 11,0735 & 8,2776 \\
\hline Mínimo & 0,00 & 0,00 & 0,00 & 0,00 & 0,00 & 0,00 & 0,00 & 0,00 & 13,00 \\
\hline Máximo & 27,00 & 1,00 & 0,94 & 1.00 & 1,00 & 1,00 & 36,72 & 38,96 & 51,00 \\
\hline
\end{tabular}

Legenda: $C O B=$ cobertura de analistas; SETOR = setor no qual a empresa está inserida, (alto impacto ambiental de acordo com a Lei n. 10.165/2000 - extração e tratamento de minerais; metalurgia; papel e celulose; química; transporte) e zero para não sensíveis; $A L A V=$ alavancagem medida pelo Passivo Exigível Total/Ativo Total; INTER = internacionalização, sendo 1 para empresas com ações listadas nos EUA e Europa e zero para não listadas; AUD = auditoria, sendo 1 para Big Four (Ernst \& Young Terco, Deloitte Touche Thmatsu, KPMG e PricewaterhouseCoopers) e zero para as demais; FUNDOS = Fundos socialmente responsáveis, sendo 1 para empresas listadas no $I S E$ e $I C O$ da $B^{3}$, zero para as demais; $R E C=L n$ de receita líquida total; ATIVO $=$ Ln de ativo total; ISD = índice de social disclosure. $D P=$ desvio-padrão.

De início, verifica-se que a quantidade média de analistas aumentou em aproximadamente $35 \%$ no período de 2010-2014, passando de 11 analistas em média (2005-2009) para aproximadamente 15 (2010-2014). Essa tendência nos dados poderá em princípio, ter contribuído para um maior nível de social disclosure. 
Contudo, apesar do aumento médio na quantidade de analistas, o que se verifica, em média, é uma diminuição no nível de social disclosure, passando de 29 pontos (2005-2009) para 28 pontos (20102014). Essa mesma tendência é observada pela mediana dos períodos. Por outro lado, ao se analisar a evidenciação no período total (2005-2014), a mediana é de 31 pontos, exatamente igual ao período de 2005-2009, que apresentou maior volume de informações. Apesar dessa constatação, verifica-se que há uma diferença de 7 pontos entre a empresa de maior divulgação identificada em 2005-2009 e a do período de 2010-2014.

Um dos motivos para essa queda na divulgação pode estar no tamanho médio apresentado pelas empresas da amostra, haja vista que estudos anteriores (Campbell, Moore \& Shrives, 2006; Clarkson et al., 2008; Murcia \& Santos, 2009; Rover, 2013; Gonçalves et. al., 2014) apontam que quanto maior for a empresa maior deve ser o nível de evidenciação. Entretanto, o que se observa é que há uma diminuição no tamanho das empresas da amostra ao se observar a mediana das variáveis de receita ( $\mathrm{rec}=26,43$ no período de 2005-2009 e 23,02 em 2010-2014) e ativo (30,13 no período de 2005-2009 e 25,74 em 2010-2014).

Não menos importante, observa-se que a maior parte das empresas pertence a setores não sensíveis ( mediana $=$ zero) e de empresas listadas em bolsas internacionais (mediana $=1$ ) para ambos os períodos . Se por um lado as empresas de setores não sensíveis apresentam menores níveis de social disclosure, por outro, empresas listadas em bolsas internacionais possuem melhores práticas de divulgação, incluindo as de natureza social (Gray et. al.; 2001; Richardson \& Welker, 2001). A fim de se analisar a tendência do nível de social disclosure no período do estudo, foi realizada uma análise por quartis, conforme a seguir.

A variável índice de social disclosure (ISD) foi analisada sob a ótica qualidade da informação disponível nos 719 documentos examinados. Para Gonçalves et al. (2012, p.102) o nível de social disclosure pode ser assim classificado em quartis, nos quais, até 22 pontos o nível de social disclosure é considerado ruim; entre 22 a 30 pontos o nível de social disclosure é considerado baixo; entre 31 a 34 pontos o nível de social disclosure é considerado médio e acima de 34 pontos é considerado alto.

Assim sendo, para saber a tendência do nível de social disclosure, foram elaboradas as tabelas $3 \mathrm{e}$ 4 , sendo que a tabela 4 busca evidenciar a referida variável em conjunto com a variável cobertura de analistas.

\begin{tabular}{|c|c|c|c|c|c|c|c|c|c|c|}
\hline \multirow{2}{*}{ Ano } & \multicolumn{2}{|c|}{ Ruim } & \multicolumn{2}{|c|}{ Baixo } & \multicolumn{2}{|c|}{ Médio } & \multicolumn{2}{|c|}{ Alto } & \multicolumn{2}{|c|}{ Total } \\
\hline & $\%$ & Quant. & $\%$ & Quant. & $\%$ & Quant. & $\%$ & Quant. & $\%$ & Quant. \\
\hline 2005 & $11,63 \%$ & 5 & $30,23 \%$ & 13 & $18,60 \%$ & 8 & $39,53 \%$ & 17 & $100 \%$ & 43 \\
\hline 2006 & $18,37 \%$ & 9 & $14,29 \%$ & 7 & $38,78 \%$ & 19 & $28,57 \%$ & 14 & $100 \%$ & 49 \\
\hline 2007 & $30,30 \%$ & 20 & $16,67 \%$ & 11 & $25,76 \%$ & 17 & $27,27 \%$ & 18 & $100 \%$ & 66 \\
\hline 2008 & $28,17 \%$ & 20 & $22,54 \%$ & 16 & $18,31 \%$ & 13 & $30,99 \%$ & 22 & $100 \%$ & 71 \\
\hline 2009 & $18,92 \%$ & 14 & $28,38 \%$ & 21 & $21,62 \%$ & 16 & $31,08 \%$ & 23 & $100 \%$ & 74 \\
\hline 2010 & $26,92 \%$ & 21 & $17,95 \%$ & 14 & $34,62 \%$ & 27 & $20,51 \%$ & 16 & $100 \%$ & 78 \\
\hline 2011 & $23,17 \%$ & 19 & $28,05 \%$ & 23 & $23,17 \%$ & 19 & $25,61 \%$ & 21 & $100 \%$ & 82 \\
\hline 2012 & $20,24 \%$ & 17 & $35,71 \%$ & 30 & $20,24 \%$ & 17 & $23,81 \%$ & 20 & $100 \%$ & 84 \\
\hline 2013 & $22,09 \%$ & 19 & $26,74 \%$ & 23 & $24,42 \%$ & 21 & $26,74 \%$ & 23 & $100 \%$ & 86 \\
\hline 2014 & $22,09 \%$ & 19 & $33,72 \%$ & 29 & $19,77 \%$ & 17 & $24,42 \%$ & 21 & $100 \%$ & 86 \\
\hline
\end{tabular}

Ao se analisarem os resultados acima, não se percebe uma tendência de melhoria na qualidade das informações sociais divulgadas pelas empresas, no transcorrer do período estudado. O percentual de empresas classificadas como "ruim" começa com 11,63\% em 2005, alcança 30,30\% em 2007 e encerra, em 2014, com 22,09\%, um resultado final bem acima do início da série. Corroborando essa tendência, verifica-se também que foi reduzido o percentual de empresas que alcançaram o nível "alto" de 
evidenciação social, iniciando a série com 39,53\% e encerrando, em 2014, com apenas $24,42 \%$. Ainda assim, por mais que o percentual de empresas classificadas com alto índice de evidenciação social se mantenha superior ao percentual de empresas classificadas com grau de evidenciação social "ruim", nesta primeira análise, verifica-se uma tendência de piora na qualidade da informação social.

Adicionalmente observa-se, no início do período (2004), uma maioria de empresas (total de 17) com o nível de disclosure classificado como alto e uma minoria (5) como ruim. Essa tendência mantém-se, ainda que com alterações, até o ano de 2009, em que se observa a maior parte das empresas com o nível de disclosure classificadas como alta (21) e uma minoria como ruim (14).

Contudo, a partir de 2010 a quantidade de empresas classificadas como ruim já atinge 21 (27\%) enquanto que aquelas classificadas como alta somam 16 (21\%). Essa tendência de menor divulgação persiste durante todo o período subsequente, à medida que se encerra com 29 empresas (34\%) classificadas como baixo, sendo estas as de maior representação para o ano de 2014.

Por mais importante que seja um maior nível e qualidade de informação para a tomada de decisão à todos os usuários, não se atesta que as empresas componentes desta amostra estejam inseridas em um movimento de maior social disclosure, rejeitando-se, neste primeiro momento, a $\mathrm{H}_{2}$.

A fim de se ter a evolução entre nível de social disclosure e cobertura de analistas a Tabela 4 apresenta o cruzamento dos dados para o período total entre 2005 a 2014.

Tabela 4: Quantidade de empresas por nível de Social Disclosure e de cobertura dos analistas de mercado - período de 2005 a 2014

\begin{tabular}{|c|c|c|c|c|c|c|c|c|}
\hline \multirow{3}{*}{ Cobertura de analistas } & \multirow{3}{*}{$\begin{array}{c}\text { Nível de Social } \\
\text { Disclosure } \\
\text { Alto } \\
\text { (> de } 34)\end{array}$} & \multicolumn{6}{|c|}{ Nível de Social Disclosure } & \multirow{3}{*}{$\%$} \\
\hline & & \multirow{2}{*}{$\%$} & Médio & \multirow{2}{*}{$\%$} & Baixo & \multirow{2}{*}{$\%$} & Ruim & \\
\hline & & & (de 31 a 34) & & (de 22 a 30 ) & & (< de 22$)$ & \\
\hline Alta (acima de 16) & 95 & $48,72 \%$ & 61 & $35,06 \%$ & 40 & $21,39 \%$ & 28 & $17,18 \%$ \\
\hline Média (de 14 a 16) & 52 & $26,67 \%$ & 44 & $25,29 \%$ & 37 & $19,79 \%$ & 22 & $13,50 \%$ \\
\hline Baixa (de 9 a 13) & 34 & $17,44 \%$ & 34 & $19,54 \%$ & 63 & $33,69 \%$ & 57 & $34,97 \%$ \\
\hline Muito baixa (abaixo de 9) & 14 & $7,18 \%$ & 35 & $20,11 \%$ & 47 & $25,13 \%$ & 56 & $34,36 \%$ \\
\hline Total de observações & 195 & $100 \%$ & 174 & $100 \%$ & 187 & $100 \%$ & 163 & $100 \%$ \\
\hline
\end{tabular}

Analisando-se a relação entre as variáveis no período total de 2005 a 2014, observa-se que, quanto maior o nível de evidenciação social, maior é a quantidade de empresas acompanhadas por um maior número de analistas de mercado. Em números, $48,72 \%$ das empresas classificadas como de alto nível de evidenciação social tinham também uma alta cobertura dos analistas de mercado, ao passo que apenas $7,18 \%$ possuíam muito baixa cobertura dos analistas. Corroborando este resultado, ao se analisar a quantidade de empresas classificadas com grau de evidenciação social "ruim", apenas 17,17\% detinham uma alta cobertura dos analistas de mercado, enquanto que outras $34,36 \%$ possuíam uma cobertura muito baixa.

Os resultados iniciais da análise descritiva vão ao encontro da $\mathrm{H}_{1}$ da pesquisa em que empresas com maior nível de evidenciação social possuem maior cobertura por parte dos analistas de mercado.

Desse modo, a fim de testar $\mathrm{H}_{1}$ foram especificados três modelos econométricos com objetivo de analisar o efeito da variável cobertura de analistas em relação ao nível de evidenciação social (variável dependente): a) modelo 1 - em razão da convergência às normas internacionais elaborou-se um modelo compreendendo o período de 2005 a 2009 (ano anterior a obrigatoriedade da adoção às normas internacionais de contabilidade); b) modelo 2 - compreende o período pós adoção às normas internacionais de contabilidade analisado neste estudo (2010 a 2014); e c) modelo 3 - compreende todo o período 
(2005 a 2014), no qual, para controlar os efeitos dos diferentes padrões contábeis nos períodos analisados, foi inserida a variável dummy - convergência. Ressalta-se que, além de controlar os efeitos dos diferentes padrões contábeis, essa variável permitirá inferir se a diminuição no nível de evidenciação, conforme demonstrado na análise precedente, é estatisticamente significativa, esperando-se um sinal negativo em relação à variável dependente.

Os modelos econométricos foram estimados considerando-se os testes de robustez e a metodologia mais adequada aos dados amostrais. As três equações foram estimadas pelo método SUR (Seemingly Unrelated Regressions), robusto para heteroscedasticidade e correlação cross-seccional entre resíduos.

Foram realizados testes de raiz unitária no conjunto das variáveis para os três modelos. Os testes revelaram que as variáveis são estacionárias, não havendo assim o risco de regressões espúrias.

Os testes de redundância de efeitos fixos revelaram que é indiferente utilizar efeitos fixos ou pooled para se realizar as regressões. Porém, de acordo com o teste de Hausman, o modelo de efeitos fixos se mostrou mais adequado à realidade do modelo e, portanto, a heterogeneidade foi capturada pela constante, em cross-section. Assim sendo, a seguir são apresentados os resultados das regressões, conforme Tabela 5.

Tabela 5: Resultados das regressões - Variável dependente - índice de social disclosure (ISD)

$I S D_{i t}=\beta_{i}+\beta_{2} C_{i t}+\beta_{3} S_{i}+\beta_{4} T_{i t}+\beta_{5} E_{i t}+\beta_{6} I_{i t}+\beta_{7} A_{i t}+\beta_{8} F_{i t}+\varepsilon_{i t}$ (1)

\begin{tabular}{|c|c|c|c|c|}
\hline Variável & $\begin{array}{c}\text { Sinal } \\
\text { esperado }\end{array}$ & $\begin{array}{c}\text { Estatística t } \\
\text { (p-valor) } \\
(2005 \text { a } \\
2009)\end{array}$ & $\begin{array}{c}\text { Estatística t } \\
\text { (p-valor) } \\
(2010 \text { a } \\
2014)\end{array}$ & $\begin{array}{c}\text { Estatística t } \\
\text { (p-valor) } \\
(2005 \text { a } \\
2014)\end{array}$ \\
\hline $\begin{array}{l}\text { Cobertura de analistas } \\
\text { (C) }\end{array}$ & $(+)$ & $\begin{array}{c}3.0732^{* * *} \\
(0.0023)\end{array}$ & $\begin{array}{l}2.4851 * * \\
(0.0134)\end{array}$ & $\begin{array}{c}4.0699 * * * \\
(0.0001)\end{array}$ \\
\hline Setor (S) & $(+)$ & $\begin{array}{c}3.0732^{* * * *} \\
(0.0023)\end{array}$ & $\begin{array}{c}4.9009^{* * *} \\
(0.0000)\end{array}$ & - \\
\hline Tamanho (T) & $(+)$ & $\begin{array}{c}6.0862^{* * * *} \\
(0.0000)\end{array}$ & $\begin{array}{c}6.0286^{* * *} \\
(0.0000)\end{array}$ & $\begin{array}{c}0.7300 \\
(0.4656)\end{array}$ \\
\hline Endividamento (E) & $(+)$ & $\begin{array}{c}0.5567 \\
(0.5781)\end{array}$ & $\begin{array}{l}1.8663^{*} \\
(0.0627)\end{array}$ & $\begin{array}{c}0.6766 \\
(0.4989)\end{array}$ \\
\hline Internacionalização (I) & $(+)$ & $\begin{array}{c}0.3066 \\
(0.7593)\end{array}$ & $\begin{array}{l}-1.2124 \\
(0.2261)\end{array}$ & $\begin{array}{l}2.0984^{* *} \\
(0.0363)\end{array}$ \\
\hline Auditoria (A) & $(+)$ & $\begin{array}{l}3.0052^{* * *} \\
(0.0029)\end{array}$ & $\begin{array}{c}0.3100 \\
(0.7567)\end{array}$ & $\begin{array}{l}-0.2146 \\
(0.8301)\end{array}$ \\
\hline Fundos Sustentáveis (F) & $(+)$ & $\begin{array}{c}4.2065^{* * *} \\
(0.0000)\end{array}$ & $\begin{array}{c}5.5087^{* * *} \\
(0.0000)\end{array}$ & $\begin{array}{c}2.4508^{* * *} \\
(0.0145)\end{array}$ \\
\hline Convergência (Conv) & $(+/-)$ & - & - & $\begin{array}{l}-1.9518^{*} \\
(0.0514)\end{array}$ \\
\hline Constante & & $\begin{array}{l}-4.3129 \\
(0.0000)\end{array}$ & $\begin{array}{l}-3.0994 \\
(0.0021)\end{array}$ & $\begin{array}{c}11,420 \\
(0,0000)\end{array}$ \\
\hline Efeitos & & Fixos & Fixos & Fixos \\
\hline$N^{\circ}$ de observações & & 302 & 413 & 715 \\
\hline Estatística F & & 31.89059 & 17.63614 & 22.44189 \\
\hline Probabilidade F & & 0,00000 & 0,00000 & 0,00000 \\
\hline R2 ajustado & & 0.530272 & 0.307560 & 0.734515 \\
\hline DW & & 0.698540 & 0.495910 & 1.340035 \\
\hline
\end{tabular}

Nota: $C=$ Cobertura de analistas mensurado pelo Ln do total de analistas de mercado da empresa i no momento $t ; T=$ Tamanho mensurado pelo Ln do total de receita operacional líquida (período 2005-2014) e pelo Ln do ativo total da empresa i no período t no período de 2005-2009 e 2010-2014; S = Setor, sendo 1 para sensíveis (alto impacto ambiental de acordo com a Lei n $10.165 / 2000$ - extraçáo e tratamento de minerais; metalurgia; papel e celulose; química; transporte) e zero para náo sensiveis; I=Internacionalização sendo 1 para empresas com açóes listadas nos EUA e Europa e zero para não listadas; A = Auditoria sendo 1 para Big Four (Ernst \& Young Terco, Deloitte Touche Thmatsu, KPMG e Pricewaterhouse Coopers) e zero para demais; = Fundos socialmente responsaveis, sendo 1 para empresas listadas nol SE elCO da B' zero para demais; $A$ = Alavancagem Passivo Exigivel Total/Ativo Total. No terceiro modelo foi inserida a variavel Conv = Convergencia = variavel binaria sendo para o periodo que compreende a adoção pelas empresas brasileiras às normas internacionais (2010 em diante) e 0 para o período anterior. As estatísticas t estão entre parênteses abaixo dos coeficientes. ****** $e^{*}$ indicam a significância ao nível de $1 \%, 5 \%$ e $10 \%$, respectivamente. Por questão de espaço, foram suprimidos os valores dos efeitos fixos seccionais associados a cada empresa da amostra (2005-2014) e para ao periodo (2005 a 2009; 2010 a 2014). Do total das 719 observaçoes do estudo, 4 observaçoes náo foram estimadas em virtude da auséncia da informaçáo acerca da cobertura de analistas para a
mencionada empresalano. 
Nota-se que as regressões estimadas para os três períodos permitem rejeitar a hipótese nula de ausência de regressão, conforme estatística $F(p$-valor $<0,01$ ) e as regressões explicam, aproximadamente, 53\% (2005-2009), 31\% (2010-2014) e 73\% (2005-2014) das variações da variável dependente Índice de Social Disclosure.

A variável Cobertura dos analistas apresentou relação positiva e significativa com a variável ISD nas três regressões estimadas, o que corrobora a análise descritiva deste estudo e segue a linha da hipótese da pesquisa, de que uma maior cobertura dos analistas de mercado traz consigo maiores níveis de social disclosure.

Apesar da significância da variável - cobertura de analistas - para o segundo período, salienta-se que na análise descritiva dos dados, seção anterior, os anos de 2013 e 2014, que estão incluídos neste mesmo corte temporal, não apresentaram, entre as variáveis, resultados positivos tão relevantes como nos anos anteriores, o que indica possível mudança de comportamento da variável que avalia o nível de evidenciação. Uma possível explicação para esse comportamento é o fato da mudança no padrão informacional da GRI-G4, evidenciando a resposta do gestor quanto aos incentivos mencionados por Verrecchia (2001) na divulgação discricionária baseada no julgamento.

Para compreender melhor o comportamento das variáveis (listagem em fundos socialmente responsáveis, nível de evidenciação e cobertura de analistas), verificando se há alguma precedência entre elas, de forma a ajudar a explicar o comportamento de uma em relação a outra, realizou-se o teste de causalidade de Granger.

Tabela 6: Teste de Causalidade Granger

\begin{tabular}{|c|c|c|c|}
\hline $\begin{array}{l}\text { Amostra: } 1.685 \\
\text { Hipótese Nula: }\end{array}$ & Lags: 2 & Estatística-F & P-Valor \\
\hline \multicolumn{2}{|c|}{$\begin{array}{l}\text { Fundos não Causa Granger ISD } \\
\text { ISD não Causa Granger Fundos }\end{array}$} & $\begin{array}{l}1,02319 \\
8,22454\end{array}$ & $\begin{array}{l}0,3600 \\
0,0003\end{array}$ \\
\hline \multicolumn{2}{|c|}{$\begin{array}{l}\text { Cobertura não Causa Granger Fundos } \\
\text { Fundos não Causa Granger Cobertura }\end{array}$} & $\begin{array}{l}4,45915 \\
0,06193\end{array}$ & $\begin{array}{l}0,0119 \\
0,9400\end{array}$ \\
\hline \multicolumn{2}{|c|}{$\begin{array}{l}\text { Cobertura não Causa Granger ISD } \\
\text { ISD não Causa Granger Cobertura }\end{array}$} & $\begin{array}{l}1,00604 \\
1,43383\end{array}$ & $\begin{array}{l}0,3662 \\
0,2391\end{array}$ \\
\hline
\end{tabular}

Nota: Cobertura = Cobertura de analistas; Fundos =

Listagem Fundos Socialmente Responsáveis e ISD = índice de social disclosure

Analisando a Tabela 6, pode-se afirmar que o nível de social disclosure causa no sentido Granger (precede), a entrada das empresas em fundos socialmente responsáveis, o que indica a necessidade de as empresas de melhorarem seus níveis de evidenciação para conseguirem ingressar na carteira do ISE, o mesmo acontecendo com a cobertura de analistas, que precedeu a adesão das empresas ao índice de sustentabilidade empresarial. Nesse sentido, é possível inferir que o aumento da cobertura dos analistas devido ao maior nível de evidenciação, ocorre em momento anterior à entrada da empresa no ISE.

É possível afirmar, portanto, que a cobertura de analistas não causa no sentido Granger o nível de social disclosure e vice-versa, ou seja, os efeitos são contemporâneos, indo ao encontro dos resultados das regressões evidenciadas na Tabela 5.

As regressões baseadas na equação (2), destinadas a testar a persistência do ISD foram também estimadas e os seus resíduos foram testados para correlação serial, heteroscedasticidade e normalidade. Os resultados dessas regressões e dos respectivos testes, por ocuparem um longo espaço, estão apresentados no Apêndice 1, no final do artigo.

Em princípio, seriam 86 regressões, uma para cada empresa. No entanto, as empresas $8,17,34$, 38,61 e 67 , mantiveram o ISD constante por todo o período, sendo, portanto, persistentes (7\% das empresas da amostra). Porém, por este motivo, não foi possível estimar as respectivas regressões pela 
inevitável ocorrência de matriz singular. As empresas 41, 53, 62 e 74 foram descartadas por ocorrência de micronumerosidade (dados insuficientes para estimação). As regressões relativas às empresas 9,30 , $32,39,40,42,45,46,63,64,69,71,73,83$ e 86 , isto é, $17 \%$ da amostra revelaram persistência do ISD, pois tiveram o coeficiente $\beta$ significante, pelo menos a $10 \%$. Dentre essas regressões com evidências de persistência do ISD, os testes realizados indicam ausência de correlação serial, de heteroscedasticidade e de não-normalidade, exceto a regressão referente à empresa 64 , cujo teste de heteroscedasticidade (White) levou à rejeição da hipótese nula de homoscedasticidade.

De certa forma, pode-se traçar o seguinte paralelo com relação ao caminho percorrido pelas empresas cujo resultado é o ingresso em listagem em fundos socialmente responsáveis (ISE):

1. Com objetivo de ingressarem no ISE, as empresas aumentam o nível de social disclosure - trata-se de uma resposta à um incentivo exógeno, em que empresas que realizam ações de responsabilidade social com objetivo de melhorar reputação organizacional passam a ter maior cobertura da imprensa especializada, como afirmam Jo e Harjoto (2014);

2. Os analistas passam a se interessar pela empresa em razão da maior evidenciação que estas proporcionam, dado que possibilita análises mais completas e diversificadas, o que dá maior relevância aos relatórios elaborados (Jo \& Harjoto, 2014; Cahan et al., 2014) ou ainda, a expectativa de que os mesmos permitam melhor previsibilidade nos resultados futuros (Dhaliwall et al., 2012; Lee, 2017);

3. A empresa começa a cumprir os requisitos necessários para compor o ISE, com base nas informações divulgadas, e o mercado passa a convergir para esta decisão (listagem da empresa no fundo).

Esse resultado é especialmente útil porque vai ao encontro, em certa medida, dos estudos de Dhaliwall et al. (2012), Cormier e Magnan (2014) e Lee (2017) em que empresas socialmente responsáveis possuem melhores práticas de evidenciação incentivadas por uma maior exposição (Jo \& Harjoto, 2014), resultado de uma maior cobertura de analistas.

Por outro lado, não é possível afirmar que há uma precedência na relação entre nível de evidenciação e cobertura dos analistas, isto é, as variáveis evoluem de forma contemporânea, sem que uma preceda a outra. Desse modo a $\mathrm{H}_{1}$ pode ser corroborada nesse sentido, em que empresas com maior cobertura de analistas possuem um maior social disclosure (Jo \& Harjoto; 2014; Cahan et. al., 2014).

Melhores práticas de divulgação dizem respeito ao fato, segundo Parsa e Kouhy (2001) e Beuren et. al. (2010), de que se espera em empresas socialmente responsáveis, de que os usuários sejam providos de informações mais completas e fidedignas, com menor assimetria da informação (Lee, 2017), permitindo uma melhor precificação do risco sistemático, inclusive a diminuição do custo de capital (Dhaliwall et. al., 2011; Gonçalves et. al., 2013).

Contudo, não é possível afirmar que há um crescimento de persistência ao longo do período de melhoria na divulgação de tais informações $\left(\mathrm{H}_{2}\right)$, apesar dos incentivos identificados para uma maior divulgação.

Inicialmente porque observa-se que o sinal da variável convergência está negativamente relacionado com o nível de social disclosure, indicando que a partir de 2010 há uma diminuição na divulgação dessa informação. Esse resultado corrobora a tendência observada na análise descritiva dos dados, em que empresas classificadas com o nível de social disclosure como ruim passam de 11,65\% em 2005, 30,30\% em 2007 e 22,09\% em 2014; enquanto empresas classificadas com o nível alto iniciam em 39,53\% (ano de 2005) e encerram em 24,42\% (ano de 2014).

É relevante destacar que no período analisado o tamanho das empresas da amostra diminuiu em aproximadamente $15 \%$, ao se comparar a mediana do ativo total do período de $2005-2009(30,13)$ e 
do período de 2010-2014 (25,74). Considerando que o tamanho é uma das variáveis relevantes no que tange ao nível de evidenciação (Campbell, Moore \& Shrives, 2006; Clarkson et al., 2008; Murcia \& Santos, 2009; Rover, 2013; Gonçalves et. al., 2014) essa queda pode ser parcialmente explicada pela mudança dessa característica.

Adicionalmente, verifica-se a partir dos resultados da equação (2) que testou se há uma persistência na divulgação do social disclosure no período de 2005 a 2014, constatou-se ao nível de significância de pelo menos $10 \%$ que em $24 \%$ das empresas da amostra há uma persistência na divulgação (17\% via regressão e 7\% pela constância do ISD), enquanto que em 76\% não há. Desse modo, conclui-se, quer pela análise descritiva dos resultados, quer pelo teste quanto a persistência da divulgação, que não se verifica tendência de crescimento da divulgação e tampouco sua persistência, não corroborando, portanto, a $\mathrm{H}_{2}$ da pesquisa.

\section{CONSIDERAÇÕES FINAIS}

Com objetivo de analisar se a cobertura realizada pelos analistas de mercado proporciona maior nível da evidenciação social em empresas brasileiras abertas, foram analisadas 86 empresas abertas em uma série temporal de 10 anos (2005-2014).

Quanto aos determinantes para um maior nível de social disclosure, verificou-se que as variáveis Internacionalização e Fundos Socialmente Responsáveis foram significantes em todo período analisado (2005-2014); a variável Tamanho foi significativa nos períodos segregados (2005-2009 e 2010-2014); a variável Auditoria interferiu significativamente no primeiro período de seleção (2005-2009) e Setor e Endividamento no segundo período de seleção (2010-2014).

Ao comparar esses resultados com estudos anteriores (Campbell, Moore \& Shrives, 2006; Clarkson et al., 2008; Murcia \& Santos, 2009; Rover, 2013; Gonçalves et. al., 2014; Moraes, Gonçalves \& Niyama, 2015), que não testaram tais determinantes em conjunto com a cobertura de analistas, pode-se afirmar que esta última tem um maior poder explicativo haja vista a não significância das variáveis setor, tamanho, endividamento e auditoria no período de 2005-2014.

Quanto à cobertura dos analistas de mercado, principal fonte de apreciação desta pesquisa, esta apresentou significância quanto ao nível de social disclosure para as empresas desta amostra, durante todo o período estudado, corroborando a $\mathrm{H} 1$ da pesquisa, à medida que tanto o social disclosure pode ser visto como um redutor da assimetria informacional, como o acompanhamento por parte dos analistas de mercado interfere positivamente no nível das informações sociais apresentadas pelas empresas.

A constatação dessa evidência é relevante à medida que corrobora com o fato de que empresas socialmente responsáveis passam a ter maior atenção da imprensa especializada, isto é, maior cobertura de analistas. Essa maior visibilidade decorre do que Lee (2017) afirma, de que empresas com esta característica mitigam a assimetria informacional, proporcionando informações de maior fidedignidade e com isso melhorando as análises dos especialistas (Dhaliwall et al, 2012, Cormier \& Magnan, 2014).

Por outro lado, apesar dos benefícios que a maior divulgação traz, a H2 não foi corroborada, uma vez que se verificou a persistência na divulgação em somente $24 \%$ das empresas investigadas ( $17 \%$ com $\beta$ significante e $7 \%$ com ISD constante durante todo o período). Portanto, em $76 \%$ a informação precedente não contribui para explicar a informação futura (sendo em $5 \%$ das empresas em virtude de dados insuficientes para estimação da persistência). Ademais, a análise dos dados descritivos aponta, a partir de 2009, uma queda no nível de divulgação, o que foi corroborado, de modo estatisticamente 
significante pela variável - convergência - em razão do sinal negativo no modelo estimado para o período de 2005-2014.

Assim sendo, sugere-se para estudos posteriores que se investiguem as causas para a diminuição do nível de evidenciação social pelas empresas, bem como as características apresentadas por estas que permitem uma melhor acurácia na previsão dos analistas.

\section{REFERÊNCIAS}

Abernathy, J., Stefaniak, C., Wilkins, A., \& Olson, J. (2017). Literature review and research opportunities on credibility of corporate social responsibility reporting. American Journal of Business, 32(1), 24-41. https://doi.org/10.1108/AJB-04-2016-0013

Baron, D. P. (2001). Private politics, corporate social responsibility and integrated strategy. Journal of Economics and management strategy, 10(1), 7-45. https://doi.org/10.1111/j.1430-9134.2001.00007.x

Bhandari, A., \& Javakhadze, D. (2017). Corporate social responsibility and capital allocation efficiency. Journal of Corporate Finance, 43, 354-377. https://doi.org/10.1016/j.jcorpfin.2017.01.012

Beuren, I. M., Boff, M. L., Horn, J. E., \& Horn, M. A. (2010). Adequação da evidenciação social das empresas de capital aberto no relatório da administração e notas explicativas às recomendações da NBC T 15. Revista de Contabilidade e Organizações, 4(8), 47-68. http://dx.doi.org/10.11606/rco.v4i8.34758

Bradley, D., Gokkaya, S., \& Liu, X. (2017). Before an analyst becomes an analyst: Does industry experience matter?. The Journal of Finance, 72(2), 751-792. https://doi.org/10.1111/jofi.12466

Brennan, M. J., \& Subrahmanyam, A. (1995). Investment analysis and price formation in securities markets. Journal of financial economics, 38(3), 361-381. https://doi.org/10.1016/0304-405X(94)00811-E

Brennan, M. J., \& Tamarowski, C. (2000). Investor relations, liquidity, and stock prices. Journal of Applied Corporate Finance, 12(4), 26-37. https://doi.org/10.1111/j.1745-6622.2000.tb00017.x

Cabral, L. (2015). Living up to expectations: corporate reputation and persistence of firm performance. Strategy Science, v. 1, n. 1, p. 2-11. https://doi.org/10.1287/stsc.2015.0002

Cahan, S. F., Chen, C., Chen, L., \& Nguyen, N. (2014, August). The Business Press and Corporate Social Responsibility: Reputation, Cost of Capital, and Firm Value. In American Accounting Association Annual Meeting Session, Atlanta, GA (Vol. 5).

Calegari, I. P., Gonçalves, R. S., Serrano, A. L. M., \& Rodrigues, J. M. (2016). Efeitos da Reputação Corporativa no Custo de Capital Próprio em Empresas Brasileiras Listadas. Revista Universo Contábil, 12(1), 178. https://doi:10.4270/ruc.2016110

Campbell, D., Moore, G., \& Shrives, P. (2006). Cross-sectional effects in community disclosure. Accouting, Auditing \& Accountability Journal, 19(1), 96-114.

https://doi.org/10.1108/09513570610651966

Chung, K. H., \& Jo, H. (1996). The impact of security analysts' monitoring and marketing functions on the market value of firms. Journal of Financial and Quantitative analysis, 31(04), 493-512.

https://doi.org/10.2307/2331357

Clarkson, P. M., Li, Y., Richardson, G. D., \& Vasvari, F. P. (2008). Revisiting the relation between environmental performance and environmental disclosure: An empirical analysis. Accounting, organizations and society, 33(4), 303-327. https://doi.org/10.1016/j.aos.2007.05.003 
Cormier, D., \& Magnan, M. (2014). The impact of social responsibility disclosure and governance on financial analysts' information environment. Corporate Governance, 14(4), 467-484. https://doi.org/10.1108/ CG-01-2013-0012

Dhaliwal, D., Li, O. Z., Tsang, A., \& Yang, Y. G. (2011). Voluntary non-financial disclosure and the cost of equity capital: the initiation of corporate social resposibility reporting. The Accounting Review, 86(1), 59-100. https://doi.org/10.2308/accr.00000005

Dhaliwal, D. S., Radhakrishnan, S., Tsang, A., \& Yang, Y. G. (2012). Nonfinancial disclosure and analyst forecast accuracy: International evidence on corporate social responsibility disclosure. The Accounting Review, 87(3), 723-759.

https://doi.org/10.2308/accr-10218

Dyck, A., Morse. A., Zingales, L. (2006). Who blows the whistle on corporate fraud? Unpublished working paper. University of Toronto, Toronto, Canadá. https://doi.org/10.1016/j.jineco.2007.05.008

Elgers, P. T., Lo, M. H., \& Pfeiffer Jr, R. J. (2001). Delayed security price adjustments to financial analysts' forecasts of annual earnings. The Accounting Review, 76(4), 613-632. https://doi.org/10.2308/ accr.2001.76.4.613

Ferreira, R. N. (2004). Responsabilidade social, governança corporativa e valor das empresas. Organizações Rurais \& Agroindustriais, 6(1).

Friedman, M. (1970). The Social Responsibility of Business is to Increase its Profits. The New York Times Magazine, vol. 13, Sep. https://doi.org/10.1007/978-3-540-70818-6_14

https://doi.org/10.1007/978-3-540-70818-6_14

Gonçalves, R. D. S., Medeiros, O. R. D., \& Gonçalves, A. D. O. (2012). Evidenciação social das empresas brasileiras de capital aberto: uma análise qualitativa das ações em programas sociais externos no período de 2005 a 2009. https://doi:10.4270/ruc.2012433

Gonçalves, R. D. S., Medeiros, O. R. D., Niyama, J. K., \& Weffort, E. F. J. (2013). Social disclosure e custo de capital próprio em companhias abertas no Brasil. Revista Contabilidade \& Finanças, 24(62), 113-124.

Gonçalves, R. D. S., Medeiros, O. R. D., Weffort, E. F. J., \& Niyama, J. K. (2014). A social disclosure index for assessing social programs in Brazilian listed firms. In Accounting in Latin America (pp. 75-103). Emerald Group Publishing Limited. https://doi:10.1108/S1479-356320140000014002

Gray, R., Javad, M., Power, D. M., \& Sinclair, C. D. (2001). Social and environmental disclosure and corporate characteristics: A research note and extension. Journal of business finance \& accounting, 28(3-4), 327-356. https://doi.org/10.1111/1468-5957.00376

Hammond, K., \& Miles, S. (2004). Assessing quality assessment of corporate social reporting: UK perspectives. In Accounting Forum (Vol. 28, No. 1, pp. 61-79). Elsevier. https://doi.org/10.1016/j.accfor.2004.04.005

Haydel, B. F. (1989). A administração estratégica de programas de responsabilidade social em empresas multinacionais: percepções da alta diretoria. Revista de Administração de Empresas, 29(3), 5-29. http:// dx.doi.org/10.1590/S0034-75901989000300002

Heal, G. (2005). Corporate social responsibility: An economic and financial framework. The Geneva papers on risk and insurance Issues and practice, 30(3), 387-409. https://doi.org/10.1057/palgrave.gpp.2510037 
Healy, P. M., Hutton, A. P., \& Palepu, K. G. (1999). Stock performance and intermediation changes surrounding sustained increases in disclosure. Contemporary accounting research, 16(3), 485-520. https:// doi.org/10.1111/j.1911-3846.1999.tb00592.x

Healy, P. M., \& Palepu, K. G. (2001). Information asymmetry, corporate disclosure, and the capital markets: A review of the empirical disclosure literature. Journal of accounting and economics, 31(1), 405-440. https://doi.org/10.1016/S0165-4101(01)00018-0

Hillman, A. J., \& Keim, G. D. (2001). Shareholder value, stakeholder management, and social issues: what's the bottom line?. Strategic management journal, 125-139. https://doi: 10.1002/1097-0266(200101)22:2<125::AID-SMJ150>3.0.CO;2-H

Hooghiemstra, R. (2000). Corporate communication and impression management-new perspectives why companies engage in corporate social reporting. Journal of business ethics, 27(1), 55-68. https:// doi.org/10.1023/A:1006400707757

Houston, J. F., Lev, B., \& Tucker, J. W. (2010). To guide or not to guide? Causes and consequences of stopping quarterly earnings guidance. Contemporary Accounting Research, 27(1), 143-185. https:// doi.org/10.1111/j.1911-3846.2010.01005.x

Ioannou, I., \& Serafeim, G. (2010). The Impact of Corporate Social Responsibility on Investment Recommendations. In Academy of Management Proceedings, 1-6. Academy of Management. https://doi. org/10.5465/ambpp.2010.54493509

Irvine, P.J. (2003). The incremental impact of analyst initiation of coverage. Journal of Corporate Finance, 9(4), 431-451. https://doi.org/10.1016/S0929-1199(02)00053-6

Jo, H.; Harjoto, M. (2014). Analyst coverage, corporate social responsibility, and firm risk. Business Ethics: A European Review, v. 23, n. 3, p. 272-292. https://doi.org/10.1111/beer.12051

Lee, D. (2017). Corporate social responsibility and management forecast accuracy. Journal of Business Ethics, 140(2), 353-367. https://doi.org/10.1007/s10551-015-2713-2

Louis, H., \& Robinson, D. (2005). Do managers credibly use accruals to signal private information? Evidence from the pricing of discretionary accruals around stock splits. Journal of Accounting and Economics, 39(2), 361-380. https://doi.org/10.1016/j.jacceco.2004.07.004

Martinez, A. L. (2004). Analisando os analistas: estudo empírico das projeções de lucros e das recomendações dos analistas de mercado de capitais para as empresas brasileiras de capital aberto. Tese [Doutorado em Administração de Empresas]. São Paulo - Escola de Administração de Empresas de São Paulo da Fundação Getúlio Vargas.

Martinez, A. L. (2009). Determinantes da acurácia das previsões dos analistas do mercado de capitais. Contabilidade, Gestão e Governança, 10(2).

Martínez-Ferrero, J., Villarón-Peramato, Ó., \& García-Sánchez, I. M. (2017). Can Investors Identify Managerial Discretion in Corporate Social Responsibility Practices? The Moderate Role of Investor Protection. Australian Accounting Review, 27(1), 4-16. https://doi.org/10.1111/auar.12138

Moraes, E. A., Gonçalves, R. de S., \& Niyama, J. K. (2015). Ambiente Regulatório e Evidenciação Social: Uma Análise das Divulgações de Empresas Brasileiras Listadas na Bm\&Fbovespa. Advances in Scientific and Applied Accounting, v. 8, p. 218-243. http://dx.doi.org/10.14392/asaa.2015080205 
Murcia, F. D. R., \& Santos, A. dos (2009). Fatores determinantes do nível de disclosure voluntário das companhias abertas no Brasil. Revista de Educação e Pesquisa em Contabilidade (REPeC), 3(2), 72-95. http://dx.doi.org/10.17524/repec.v3i2.68

Orlitzky, M., \& Benjamin, J. D. (2001). Corporate Social Performance and Firm Risk: A Meta-Analytic Review. Business Society, vol. 40, n.4, p.369-396.

Parsa, S., \& Kouhy, R. (2001). Disclosure of social information by UK companies: a case of legitimacy theory. Global business \& economics review.

Ramanathan, K. V. (1976). Toward a theory of corporate social accounting. The Accounting Review, 51(3), 516-528.

Reverte, C. (2012). The Impact of Better Corporate Social Responsibility Disclosure on the Cost of Equity Capital. Corp. Soc. Responsib. Environ. Mgmt., v. 19, jun., p.253-272. https://doi.org/10.1002/csr.273

Richardson, A. J., \&Welker, M. (2001). Social disclosure, financial disclosure and the cost of equity capital. Accounting, organizations and society, 26(7), 597-616. https://doi.org/10.1016/S0361-3682(01)00025-3

Riahi-Belkaoui, A., \& Karpik, P. G. (1989). Determinants of the corporate decision to disclose social information. Accounting, Auditing \& Accountability Journal, 2(1). https://doi.org/10.1108/09513578910132240

Riahi-Belkaoui, A. (2004). Accounting Theory. $5^{\text {a }}$ edition. London: Thomson Learning. Cengage learning EMEA.

Roberts, P.W., \& Dowling, G. R. (2002). Corporate reputation and sustained superior financial performance. Strategic management journal, 23(12), 1077-1093. https://doi.org/10.1002/smj.274

Roulstone, D. T. (2003). The relation between insider-trading restrictions and executive compensation. Journal of Accounting Research, 41(3), 525-551. https://doi.org/10.1111/1475-679X.00115

Rover, S. (2013). Disclosure Socioambiental e custo de capital próprio de companhias abertas no Brasil. 193 f. Tese [Doutorado em Ciências Contábeis] - Faculdade de Economia, Administração e Contabilidade, Universidade de São Paulo, São Paulo. https://doi.org/10.11606/T.12.2013.tde-15042013-133514.

Saiia, D. H., Carroll, A. B., \& Buchholtz, A. K. (2003). Philanthropy as strategy: When corporate charity "begins at home". Business \& Society, 42(2), 169-201. https://doi:10.1177/0007650303042002002

Schipper, K. (1991). Analysts' forecasts. Accounting horizons, 5 (4), 105-121.

Sloan, R. G. (1996). Do stock prices fully reflect information in accruals and cash flows about future earnings? Accounting Review, n. 71, p. 289-315.

Vasconcelos, C., Miyashiro, I., Reis, D., \& Paulo, E. (2008). A influência da cobertura das empresas de rating sobre o gerenciamento de resultados das companhias abertas brasileiras. Revista de Contabilidade e Organizações, 2(3), 37.

https://doi: $10.11606 /$ rco.v2i3.34712

Verrecchia, R. E. (2001). Essays on disclosure. Journal of accounting and economics, 32(1-3), 97-180. https://doi.org/10.1016/S0165-4101(01)00025-8

Wallace, R. O., \& Naser, K. (1995). Firm-specific determinants of the comprehensiveness of mandatory disclosure in the corporate annual reports of firms listed on the stock exchange of Hong Kong. Journal of Accounting and Public policy, 14(4), 311-368.

https://doi.org/10.1016/0278-4254(95)00042-9

Yu, F. F. (2008). Analyst coverage and earnings management. Journal of Financial Economics, 88(2), 245-271. https://doi.org/10.1016/j.jfineco.2007.05.008 
Anexo 1 - Itens para análise da evidenciação social

\begin{tabular}{|c|c|c|c|}
\hline \multirow{14}{*}{ Índice de Social Disclosure } & Dimensão & Direcionadores & Itens Evidenciados \\
\hline & \multirow{8}{*}{$\begin{array}{l}\text { Informações } \\
\text { passadas }\end{array}$} & $\begin{array}{c}\text { Avaliação } \\
\text { (Ramanathan, 1976) }\end{array}$ & $\begin{array}{l}\text { VAR001 - relação dos programas sociais com } \\
\text { os valores da empresa }\end{array}$ \\
\hline & & $\begin{array}{c}\text { Avaliação } \\
\text { (Ramanathan, 1976) }\end{array}$ & $\begin{array}{l}\text { VAR002 - Avaliação das necessidades locais } \\
\text { para realização dos programas sociais }\end{array}$ \\
\hline & & $\begin{array}{c}\text { Mensuração } \\
\text { (Ramanathan, 1976) }\end{array}$ & $\begin{array}{c}\text { VAR005 - descrição de objetivos e metas para } \\
\text { os programas sociais }\end{array}$ \\
\hline & & $\begin{array}{c}\text { Mensuração } \\
\text { (Ramanathan, 1976) }\end{array}$ & $\begin{array}{c}\text { VAR006 - recursos financeiros alocados nos } \\
\text { programas sociais }\end{array}$ \\
\hline & & $\begin{array}{c}\text { Mensuração } \\
\text { (Ramanathan, 1976) }\end{array}$ & $\begin{array}{l}\text { VAR007 - valor econômico e/ou financeiro dos } \\
\text { recursos humanos envolvidos em programas } \\
\text { de voluntariado }\end{array}$ \\
\hline & & $\begin{array}{c}\text { Mensuração } \\
\text { (Ramanathan, 1976) }\end{array}$ & $\begin{array}{l}\text { VAR008 - valor econômico e/ou financeiro dos } \\
\text { recursos materiais destinados aos programas } \\
\text { sociais }\end{array}$ \\
\hline & & $\begin{array}{c}\text { Mensuração } \\
\text { (Ramanathan, 1976) }\end{array}$ & $\begin{array}{c}\text { VAR009 - resultados sociais obtidos nos } \\
\text { programas sociais }\end{array}$ \\
\hline & & $\begin{array}{l}\text { Padrão de relatórios } \\
\text { (Ramanathan, 1976) }\end{array}$ & VAR011 - distribuição do valor adicionado \\
\hline & \multirow{3}{*}{$\begin{array}{l}\text { Prospecções de } \\
\text { ações futuras }\end{array}$} & $\begin{array}{c}\text { Avaliação } \\
\text { (Ramanathan, 1976) }\end{array}$ & $\begin{array}{l}\text { VAR003 - descrição de aspectos para melhoria } \\
\text { dos resultados socias obtidos nos programas } \\
\text { sociais. }\end{array}$ \\
\hline & & $\begin{array}{c}\text { Avaliação } \\
\text { (Ramanathan, 1976) }\end{array}$ & $\begin{array}{l}\text { VAR004 - descrição dos programas sociais } \\
\text { futuros e em andamento }\end{array}$ \\
\hline & & $\begin{array}{c}\text { Mensuração } \\
\text { (Ramanathan, 1976) }\end{array}$ & $\begin{array}{l}\text { VAR010 - projeção do fluxo de caixa futuro da } \\
\text { alocação de recursos em programas sociais }\end{array}$ \\
\hline & \multirow{2}{*}{ Acessibilidade } & $\begin{array}{l}\text { Padrão de relatórios } \\
\text { (Ramanathan, 1976) }\end{array}$ & $\begin{array}{l}\text { VAR012 - disponibilidade dos relatórios de } \\
\text { responsabilidade social }\end{array}$ \\
\hline & & $\begin{array}{l}\text { Padrão de relatórios } \\
\text { (Ramanathan, 1976) }\end{array}$ & $\begin{array}{l}\text { VAR013 - frequência da divulgação dos } \\
\text { relatórios de responsabilidade social }\end{array}$ \\
\hline
\end{tabular}

Fonte: Gonçalves et al. (2014, p. 85) - tradução livre.

Apêndice 1: Regressões AR(1) estimadas para análise da persistência

\begin{tabular}{|c|c|c|c|c|c|c|c|c|}
\hline Empresa & $\beta$ & $\begin{array}{l}\text { Erro } \\
\text { padrão }\end{array}$ & Estatística-t & $\begin{array}{c}\text { P-valor } \\
\text { (t) }\end{array}$ & $\begin{array}{c}p \text {-valor } \\
\text { BG }\end{array}$ & $\begin{array}{l}\text { p-valor } \\
\text { White }\end{array}$ & $\begin{array}{c}\mathrm{p} \text {-valor } \\
\mathrm{J}-\mathrm{B}\end{array}$ & Amostra \\
\hline 1 & 0,47 & 0,32 & 1,46 & 0,19 & & & & 9 \\
\hline 2 & 0,20 & 0,37 & 0,55 & 0,60 & & & & 10 \\
\hline 3 & $-0,31$ & 0,37 & $-0,82$ & 0,44 & & & & 10 \\
\hline 4 & $-0,04$ & 0,38 & $-0,09$ & 0,93 & & & & 10 \\
\hline 5 & 0,53 & 1,89 & 0,28 & 0,79 & & & & 8 \\
\hline 6 & $-0,25$ & 0,12 & $-1,97$ & 0,12 & & & & 7 \\
\hline 7 & 0,20 & 0,33 & 0,61 & 0,57 & & & & 8 \\
\hline 8 & \multicolumn{7}{|c|}{ MATRIZ SINGULAR } & 5 \\
\hline 9 & 0,64 & 0,32 & 1,99 & $0,08^{*}$ & 0,39 & 0,53 & 0,83 & 10 \\
\hline 10 & $-0,04$ & 0,35 & $-0,12$ & 0,91 & & & & 10 \\
\hline 11 & 0,12 & 0,28 & 0,42 & 0,69 & & & & 10 \\
\hline 12 & 0,53 & 0,34 & 1,57 & 0,16 & & & & 10 \\
\hline 13 & 0,17 & 0,35 & 0,48 & 0,65 & & & & 10 \\
\hline 14 & 0,16 & 0,20 & 0,83 & 0,44 & & & & 9 \\
\hline 15 & $-0,33$ & 0,68 & $-0,49$ & 0,66 & & & & 6 \\
\hline 16 & 0,11 & 0,39 & 0,27 & 0,80 & & & & 8 \\
\hline 17 & \multicolumn{7}{|c|}{ MATRIZ SINGULAR } & 3 \\
\hline 18 & 0,43 & 0,23 & 1,82 & 0,11 & & & & 10 \\
\hline 19 & 0,13 & 0,57 & 0,22 & 0,84 & & & & 7 \\
\hline 20 & 0,01 & 0,39 & 0,03 & 0,98 & & & & 10 \\
\hline 21 & 0,46 & 0,32 & 1,45 & 0,19 & & & & 10 \\
\hline 22 & 0,29 & 0,35 & 0,84 & 0,44 & & & & 8 \\
\hline 23 & $-0,79$ & 1,65 & $-0,48$ & 0,68 & & & & 5 \\
\hline 24 & 0,17 & 0,55 & 0,31 & 0,77 & & & & 7 \\
\hline
\end{tabular}




\begin{tabular}{|c|c|c|c|c|c|c|c|c|}
\hline 25 & $-0,11$ & 0,12 & $-0,89$ & 0,40 & & & & 10 \\
\hline 26 & 0,31 & 0,30 & 1,02 & 0,34 & & & & 10 \\
\hline 27 & 0,10 & 0,13 & 0,77 & 0,47 & & & & 10 \\
\hline 28 & 0,59 & 0,34 & 1,73 & 0,13 & & & & 10 \\
\hline 29 & 0,50 & 0,34 & 1,48 & 0,19 & & & & 9 \\
\hline 30 & 0,76 & 0,17 & 4,61 & $0,01^{* * *}$ & 0,17 & 0,23 & 0,70 & 8 \\
\hline 31 & 0,24 & 0,19 & 1,24 & 0,27 & & & & 8 \\
\hline 32 & 0,00 & 0,00 & 2,23 & $0,08^{*}$ & 0,03 & 0,01 & 0,04 & 8 \\
\hline 33 & $-0,08$ & 0,44 & $-0,17$ & 0,88 & & & & 5 \\
\hline 34 & 0,00 & 0,00 & 0,93 & 0,40 & & & & 4 \\
\hline 35 & 0,19 & 0,40 & 0,48 & 0,65 & & & & 10 \\
\hline 36 & 0,18 & 0,39 & 0,46 & 0,68 & & & & 6 \\
\hline 37 & 0,56 & 0,42 & 1,33 & 0,28 & & & & 6 \\
\hline 38 & \multicolumn{7}{|c|}{ MATRIZ SINGULAR } & 8 \\
\hline 39 & 0,64 & 0,29 & 2,25 & $0,06^{*}$ & 0,75 & 0,73 & 0,09 & 10 \\
\hline 40 & 0,54 & 0,07 & 7,75 & $0,01^{* * *}$ & & & & 8 \\
\hline 42 & 3,67 & 0,67 & 5,50 & $0,03 * *$ & 0,32 & 0,25 & 0,74 & 5 \\
\hline 43 & 0,18 & 0,23 & 0,79 & 0,45 & & & & 10 \\
\hline 44 & $-0,15$ & 0,37 & $-0,40$ & 0,70 & & & & 10 \\
\hline 45 & 1,50 & 0,24 & 6,34 & $0,00^{* * *}$ & 0,05 & 0,08 & 0,77 & 10 \\
\hline 46 & 0,56 & 0,25 & 2,28 & $0,06^{*}$ & 0,19 & 0,15 & 0,79 & 10 \\
\hline Empresa & $\beta$ & $\begin{array}{l}\text { Erro } \\
\text { padrão }\end{array}$ & Estatística-t & $\begin{array}{l}\text { P-valor } \\
\text { (t) }\end{array}$ & $\begin{array}{c}p \text {-valor } \\
\text { BG }\end{array}$ & $\begin{array}{l}\text { p-valor } \\
\text { White }\end{array}$ & $\begin{array}{c}p \text {-valor } \\
\text { J-B }\end{array}$ & Amostra \\
\hline 47 & 0,24 & 1,15 & 0,21 & 0,84 & & & & 9 \\
\hline 48 & $-0,36$ & 0,12 & $-2,89$ & 0,21 & & & & 4 \\
\hline 49 & $-0,43$ & 0,31 & $-1,39$ & 0,21 & & & & 10 \\
\hline 50 & 0,55 & 0,35 & 1,57 & 0,18 & & & & 8 \\
\hline 51 & $-0,33$ & 0,67 & $-0,50$ & 0,67 & & & & 5 \\
\hline 52 & 0,50 & 0,37 & 1,35 & 0,24 & & & & 8 \\
\hline 54 & 0,67 & 0,34 & 1,97 & 0,11 & & & & 8 \\
\hline 55 & 0,07 & 0,26 & 0,27 & 0,80 & & & & 8 \\
\hline 56 & 0,33 & 0,67 & 0,50 & 0,67 & & & & 5 \\
\hline 57 & $-0,26$ & 0,35 & $-0,75$ & 0,48 & & & & 10 \\
\hline 58 & 0,03 & 0,13 & 0,23 & 0,83 & & & & 8 \\
\hline 59 & 0,39 & 0,41 & 0,94 & 0,39 & & & & 9 \\
\hline 60 & $-0,25$ & 0,27 & $-0,90$ & 0,40 & & & & 10 \\
\hline 61 & \multicolumn{7}{|c|}{ MATRIZ SINGULAR } & 6 \\
\hline 63 & 0,55 & 0,29 & 1,93 & $0,09 *$ & 0,20 & 0,99 & 0,73 & 10 \\
\hline 64 & $-0,67$ & 0,25 & $-2,64$ & $0,03^{* *}$ & 0,27 & 0,01 & 0,92 & 10 \\
\hline 65 & 0,90 & 0,56 & 1,62 & 0,18 & & & & 7 \\
\hline 66 & $-0,86$ & 0,74 & $-1,15$ & 0,45 & & & & 4 \\
\hline 67 & \multicolumn{7}{|c|}{ MATRIZ SINGULAR } & 4 \\
\hline 68 & $-0,29$ & 0,25 & $-1,15$ & 0,45 & & & & 4 \\
\hline 69 & 0,64 & 0,28 & 2,30 & $0,06^{*}$ & 0,72 & 0,22 & 0,81 & 10 \\
\hline 70 & 0,28 & 0,41 & 0,69 & 0,52 & & & & 8 \\
\hline 71 & 0,85 & 0,12 & 7,00 & $0,00^{* * *}$ & 0,14 & 0,77 & 0,49 & 10 \\
\hline 72 & $-0,17$ & 0,45 & $-0,37$ & 0,74 & & & & 6 \\
\hline 73 & 0,62 & 0,26 & 2,38 & $0,05^{* *}$ & 0,88 & 0,35 & 0,18 & 10 \\
\hline 75 & 0,26 & 0,36 & 0,73 & 0,49 & & & & 10 \\
\hline 76 & 0,11 & 0,45 & 0,25 & 0,81 & & & & 8 \\
\hline 77 & 0,25 & 0,37 & 0,68 & 0,52 & & & & 10 \\
\hline 78 & 0,58 & 0,17 & 3,38 & 0,01 & & & & 9 \\
\hline
\end{tabular}




\begin{tabular}{|c|c|c|c|c|c|c|c|c|}
\hline 79 & $-0,50$ & 0,24 & $-2,12$ & 0,07 & & & & 10 \\
\hline 80 & 0,34 & 0,35 & 0,97 & 0,36 & & & & 10 \\
\hline 81 & 0,28 & 0,73 & 0,38 & 0,72 & & & & 8 \\
\hline 82 & 0,34 & 0,36 & 0,96 & 0,37 & & & & 10 \\
\hline 83 & 0,84 & 0,35 & 2,37 & $0,06^{*}$ & 0,10 & 0,18 & 0,78 & 9 \\
\hline 84 & 0,22 & 0,37 & 0,58 & 0,58 & & & & 10 \\
\hline 85 & 0,12 & 0,41 & 0,30 & 0,77 & & & & 9 \\
\hline 86 & 0,64 & 0,31 & 2,06 & $0,08^{*}$ & 0,78 & 0,45 & 0,56 & 10 \\
\hline
\end{tabular}

Obs. 1: As empresas 8, 17, 34, 38, 61 e 67, mantiveram o ISD constante por todo o período, sendo, portanto, consideradas como persistentes. Porém, por este motivo, nâo foi possivél estimar as respectivas regressóes pela inevitável ocorrência dé matriz singular

Obs. 2: As empresas 41,53, 62 e 74 foram descartadas por ocorrência de micronumerosidade (dados insuficientes para estimação).

Obs. 3: Para as regressões com $\beta$ significante a pelo menos $10 \%$, foram efetuados os testes de Breusch-Godfrey (correlação serial), White (heteroscedasticidade) e Jarque-Bera (normalidade), cujos resültados estấo relatados nas colunas 6,7 e 8 da tabela.

* Significante a $10 \% \quad * *$ Significante a $5 \% \quad * * *$ Significante a $1 \%$

